
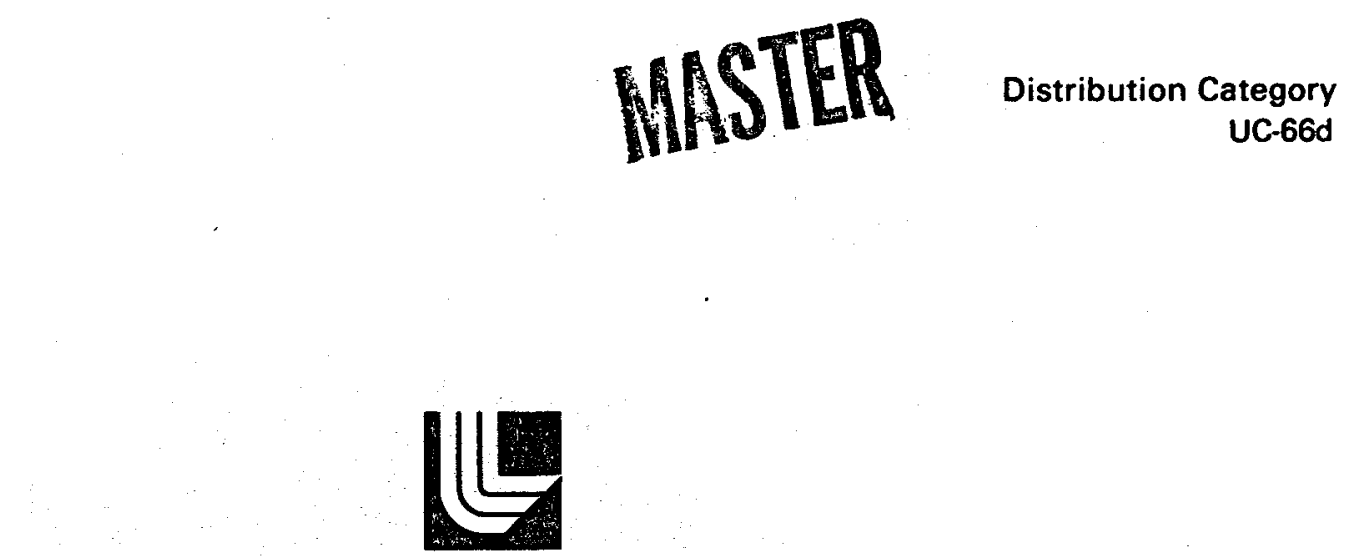

LAWRENCE LIVERMORE LABORATORY

University of Caltornia/Livermore, California, 94550

UCRL-52799

\title{
APPARATUS AND TECHNIQUES FOR THE STUDY OF PRECIPITATION OF SOLIDS AND SILICA FROM HYPERSALINE GEOTHERMAL BRINE
}

\author{
J. H. Hill, J. E. Harrar, C. H. Otto, Jr.,
}

S. B. Deutscher, H. E. Crampton, R. G. Grogan, and V. H. Hendricks

Manuscript date: July 5, 1979

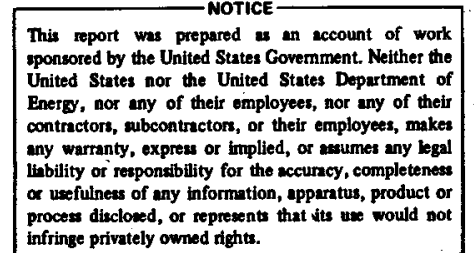




\section{DISCLAIMER}

This report was prepared as an account of work sponsored by an agency of the United States Government. Neither the United States Government nor any agency Thereof, nor any of their employees, makes any warranty, express or implied, or assumes any legal liability or responsibility for the accuracy, completeness, or usefulness of any information, apparatus, product, or process disclosed, or represents that its use would not infringe privately owned rights. Reference herein to any specific commercial product, process, or service by trade name, trademark, manufacturer, or otherwise does not necessarily constitute or imply its endorsement, recommendation, or favoring by the United States Government or any agency thereof. The views and opinions of authors expressed herein do not necessarily state or reflect those of the United States Government or any agency thereof. 


\section{DISCLAIMER}

Portions of this document may be illegible in electronic image products. Images are produced from the best available original document. 


\section{CONTENTS}

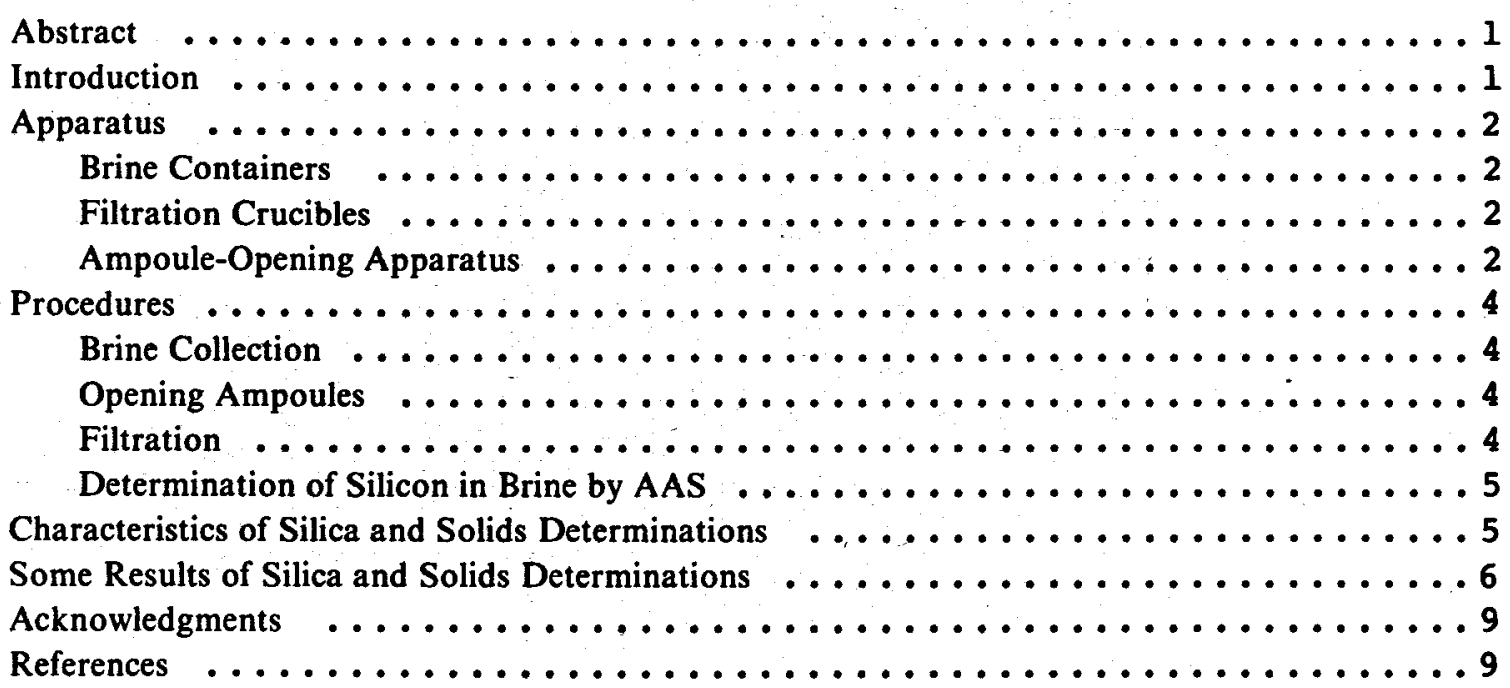




\section{APPARATUS AND TECHNIQUES FOR THE STUDY OF PRECIPITATION OF SOLIDS AND SILICA FROM HYPERSALINE GEOTHERMAL BRINE}

\section{ABSTRACT}

The kinetics of precipitation reactions in geothermal brines can be studied accurately only if the brine samples are collected and examined under anaerobic conditions and with minimum cooling. Apparatus and techniques were developed that achieve this for brine temperatures below. $100^{\circ} \mathrm{C}$. The concentration of suspended solids is measured gravimetrically after filtration, and the concentration of dissolved silica is measured by atomic absorption spectrophotometry. Data from Woolsey No. 1 well of the Salton Sea Geothermal Field illustrate typical results of the procedures.

\section{INTRODUCTION}

Two obstacles to the development of the geothermal resources of the Salton Sea Geothermal Field have been studied intensively during the past few years. One is the formation of scales (especially those rich in silica) in the piping and other plant structures as the hypersaline brine is processed. The second is the precipitation of solids (primarily silica) from the brine as it is cooled; these remain in suspension in the effluent brine and interfere with its disposal into injection wells.

To develop methods for circumventing or controlling precipitation and scaling of the brines, field laboratory techniques for investigating the kinetics of the precipitation reactions under various conditions have been established. These techniques have been used, for example, to examine the effects of acid $^{1,2}$ and organic additives ${ }^{3,4}$ on the precipitation of silica, with the goal of finding an effective agent for the control of scale. They also have been used to study the feasibility of mixing effluent brine with natural waters for injection purposes. ${ }^{5}$

This report describes in detail these techniques and the apparatus used. Data are presented that illustrate the rate of precipitation of silica from the brine from Woolsey No. I well of the Salton Sea Geothermal Field.

Many of the investigations thus far have been concerned with the fate of the effluent brine, i.e., brine that has been processed and flashed to atmospheric pressure. The temperature of the brine at the atmospheric flash is $105^{\circ} \mathrm{C}$, and in downstream equipment such as a reactor-clarifier, ${ }^{5}$ its temperature is in the range of 80 to $95^{\circ} \mathrm{C}$. It is in this temperature region that silica precipitates most rapidly and the rate of scale formation is highest. Thus the techniques described here were developed for measuring the kinetics of silica precipitation in the sub- $100^{\circ} \mathrm{C}$ range, usually at $90^{\circ} \mathrm{C}$. The behavior of the silica at higher temperatures is, of course, important to the effects of scaling there, but a kinetic study at temperatures above $105^{\circ} \mathrm{C}$ would require more elaborate, pressurized equipment. The scale-control work has concentrated on the low temperature regime because the problems must first be solved there.

The most important requirement for the study of the chemistry of these brines is that oxygen must be excluded as carefully as possible. The hypersaline brines are anoxic, and most of the dissolved species are in their reduced forms. Iron is present as +2 species and its concentration ranges from $\sim 150 \mathrm{ppm}$ in Magmamax No. 1 brine to $\sim 1500$ ppm in Sinclair No. 4 brine. The pH of these brines is between 5 and 6.5; thus when oxygen is introduced, it oxidizes the +2 iron to the +3 state, and ferric hydroxide precipitates. This will in turn substantially influence the measured rates of solids precipitation, and may affect the observed rate of precipitation of silica. Even under anaerobic conditions, there are some indications that the rates of silica precipitation and scaling increase with increasing concentrations of iron. 
The technique developed for measurement of the rates of solids and silica precipitation involves collection of the brine sample, holding it in a suitable container in an incubation oven at $90^{\circ} \mathrm{C}$, opening the container at an appropriate time, filtering the contents through either a fritted-glass crucible or membrane filter, weighing the solids on the filter after drying at $105^{\circ} \mathrm{C}$, and measuring the concentration of silica (as silicon) in the filtrate by atomic absorption spectrophotometry (AAS). Depending on how long the brine is to be incubated, two kinds of containers are used. For incubations of $2 \mathrm{~h}$ or less, the brine can be held in gasketed, screw-cap, glass bottles without detrimental ingress of air. For longer incubations, the brine is sealed in specially designed glass ampoules, which are opened with a hot-wire apparatus. Because the precipitate clings to the sides of the containers and must be removed quantitatively, widemouthed containers are required.

\section{APPARATUS}

\section{BRINE CONTAINERS}

For incubations of the geothermal brine for short intervals $(<2 \mathrm{~h})$, a standard widemouthed 130-ml (4-oz) bottle, such as Wheaton Scientific No. 221625, is used. The cap liner is removed and replaced with a Viton elastomer (Parker Seal Co. compound V747-70 or V494-70) gasket. This gasket is cut to fit from a 2- to 3-mm-thick Viton sheet. After use, the bottles are discarded and the gaskets are removed, cleaned, and reused.

For incubations of $2 \mathrm{~h}$ or more, the preferred container is the borosilicate glass ampoule shown in Fig. 1. They are custom-made from 12- and 51-mm tubing and scored as shown for later opening by the hot-wire technique. Their capacity is $\sim 165 \mathrm{ml}$.

\section{FILTRATION CRUCIBLES}

The fritted-glass crucibles for brine filtration and collection of solids are either Corning No. 32960 or Kimble No. 28260 , fine-porosity grade. These crucibles have a nominal maximum pore size of 4.5-5.5 $\mu \mathrm{m}$ as specified by ASTM test. ${ }^{6}$ These crucibles are the most convenient for handling the precipitate for further analysis; however, Nucleopore membrane filter equipment has also been used.

\section{AMPOULE-OPENING APPARATUS}

A drawing of the mechanical components and a schematic diagram of the power supply are shown, respectively, in Figs. 2 and 3. The tapped transformers are LLL Specification No. LES-21004 and the variable transformer is a Variac Type 116BU; the latter is adjusted to a setting of $\sim 65$. The heating ele-

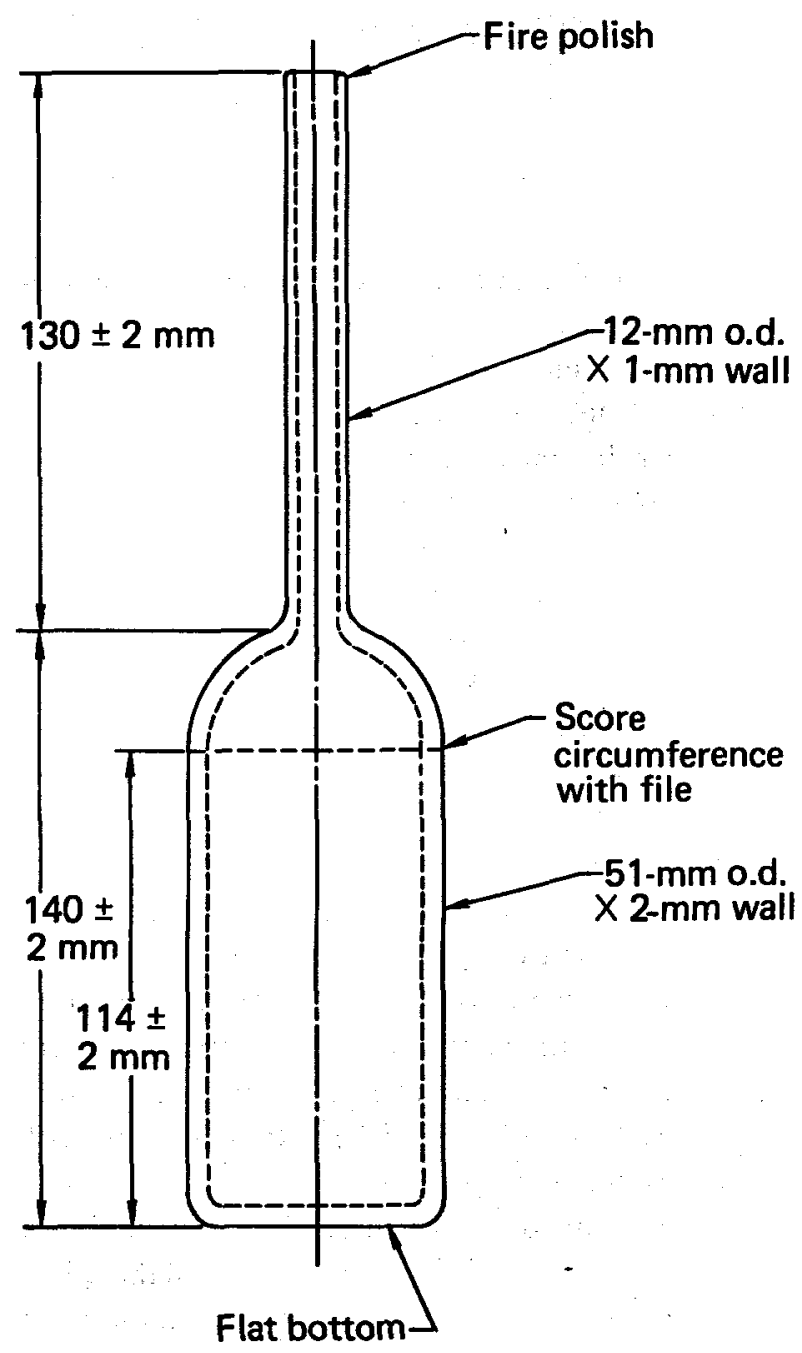

FIG. 1. Glass ampoule for incubation of geothermal brine.

ment wire, a nickel-chromium alloy, is Wilber B. Driver Co., Tophet A, No. $18(0.404 \Omega / f t)$. Two persons are required for opening an ampoule; each is 


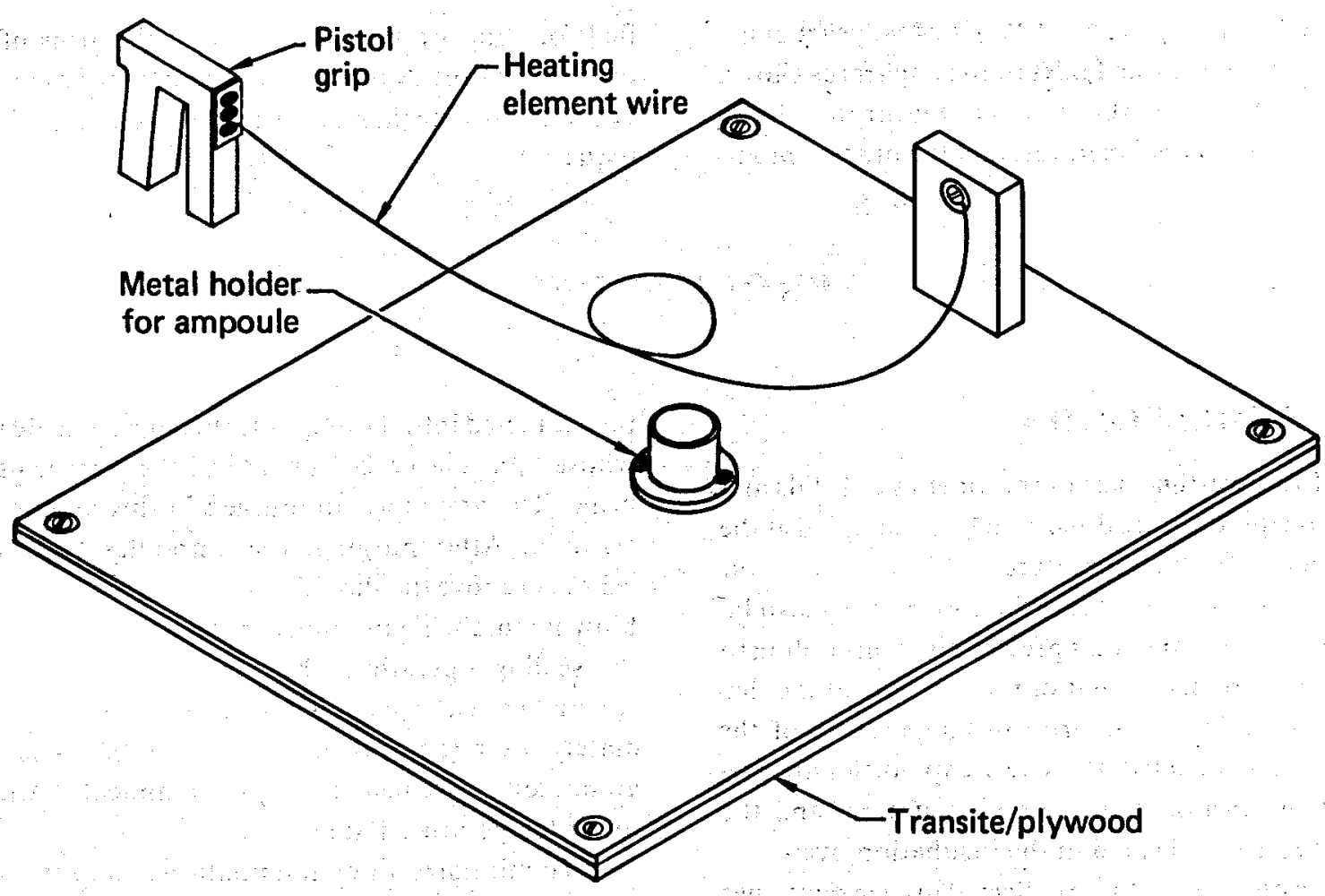

FIG. 2. Apparatus for opening glass ampoules.

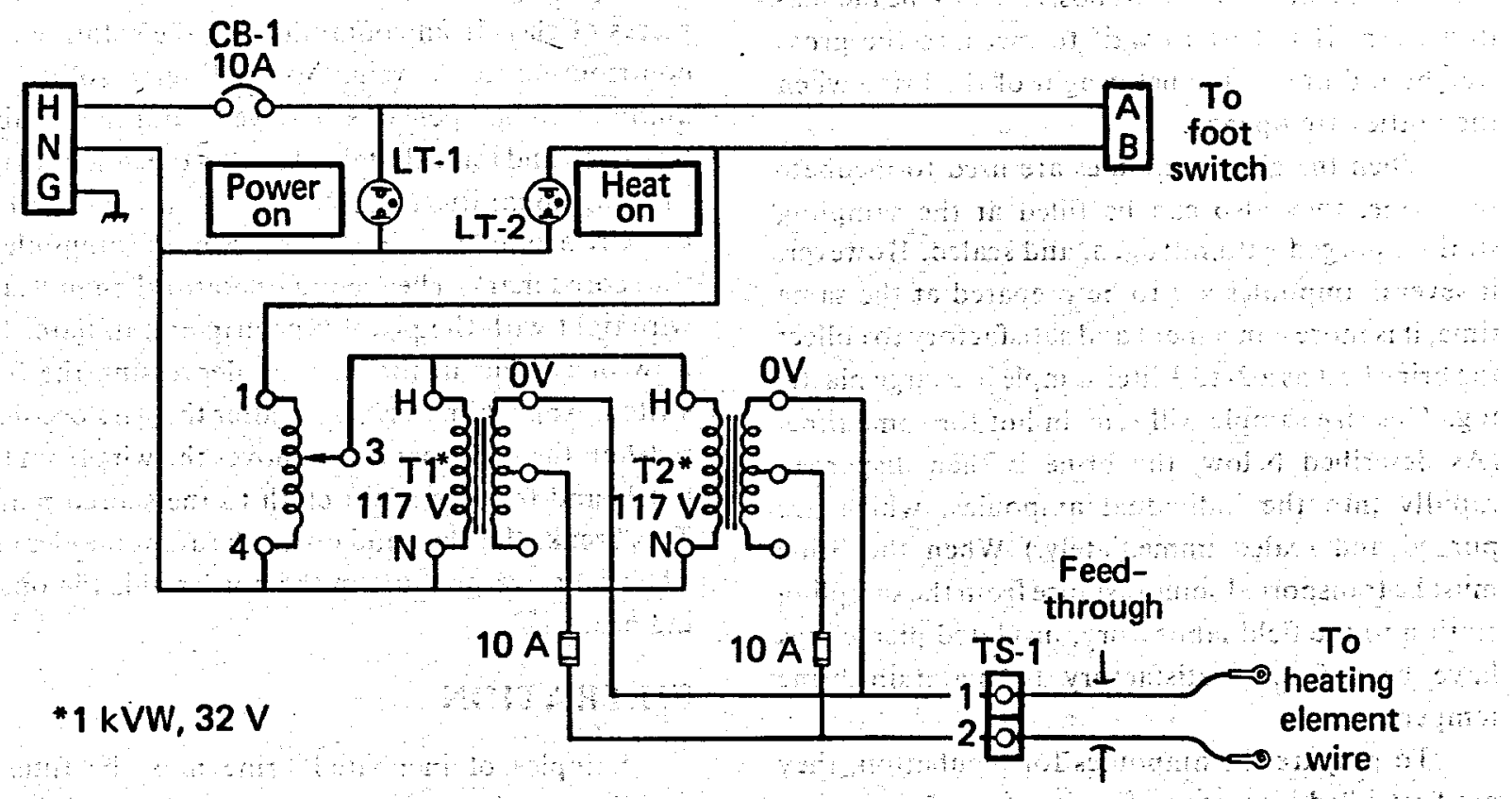

FIG. 3. Power supply for ampoule-opening apparatus. 
protected by a Nalgene No. 6350-3024 polycarbonate safety shield positioned next to the apparatus shown in Fig. 2. One of the shields has a slot for the wire to pass through to one operator, and the other is modi- fied for comfortable positioning of the arms of the other operator. A more complete construction diagram of the mechanical assembly is available on request.*

\section{PROCEDURES}

\section{BRINE COLLECTION}

Most investigations of the kinetics of solids and silica precipitation are done with brine sampled at the atmospheric flash temperature of $105^{\circ} \mathrm{C}$, so caution must be used to avoid burns. The brine must also be collected in a manner that prevents it from cooling to a temperature below that of the subsequent incubation. To minimize the drop in temperature of the brine as it is collected, the screw-cap bottles are preheated by rinsing at the sampling station, and the ampoules are preheated in the incubation oven.

The quantity of brine collected in each container is most conveniently determined by weight; therefore, before sampling, both the screw-cap bottles and the ampoules are tared.

When the brine is collected in the screw-cap bottles, they are filled completely to the top, one-byone, at the sampling station and then capped immediately and placed as soon as possible into the incubation oven. It is best to wait to measure the gross weight and obtain the net weight of the brine when the bottles are opened.

When the glass ampoules are used to incubate the brine, they also can be filled at the sampling station, purged with nitrogen, and sealed. However, if several ampoules are to be prepared at the same time, it is more convenient and satisfactory to collect the brine first as a 2- to 3-liter sample in a large plastic jug. This size sample will remain hot for some time. (As described below, the brine is then dispensed rapidly into the individual ampoules, which are purged and sealed immediately.) When the brine must be transported some distance from the sampling station to the field laboratory, insulated picnic jugs have been found satisfactory to maintain brine temperature.

To prepare the ampoules for incubation, they are first filled by means of a glass funnel to a point $\sim 1-2 \mathrm{~cm}$ below the scored mark and then weighed to obtain the gross weight. A vigorous flow of highpurity $\left(<10 \mathrm{ppm} \mathrm{O}_{2}\right)$ nitrogen or other inert gas is then directed into the ampoule through a plastic tube whose tip is placed $2-3 \mathrm{~cm}$ above the surface of the brine. The ampoules are purged in this manner for $\sim 1$ min. After purging, the ampoules are sealed $\sim 3-5 \mathrm{~cm}$ above the shoulder with a gas/oxygen glassblowing torch. To minimize the ingress of air during the sealing operation, the top of the ampoule is covered with a piece of vinyl wrapping paper immediately after removal of the purge tube. After the ampoules are sealed, the tips are annealed with a lower temperature flame.

To minimize air contamination and decrease in brine temperature, the filling and sealing operations are best done by two persons. These procedures should be completed and the ampoules returned to the incubation oven in a minimum amount of time.

\section{OPENING AMPOULES}

Opening the ampoules cleanly is essential to keep pieces of glass from contaminating the solution and contributing to the weight of the filtered solids. An ampoule to be opened is removed from the incubation oven and immediately placed in the holder of the opening apparatus (Fig. 2). One operator positions the wire around the circumference of the ampoule at the scored mark. The second operator then pulls the wire tight with the pistol-type grip and initiates the flow of current in the wire by depressing the foot switch. Approximately $30 \mathrm{sec}$ after the wire becomes red-hot, the first operator removes the wire from the bottle and touches a wet cloth to the scored mark. This breaks the glass and opens the ampoule cleanly. The slight overpressure in the bottles aids the opening process.

\section{FILTRATION}

Samples of incubated brine must be filtered rapidly after the containers are opened, to minimize

*Write to J. H. Hill or J. E. Harrar, L-325, Lawrence Livermore Laboratory, P.O. Box 808, Livermore, CA 94550. 
their temperature drop and contamination by air. The filtration apparatus consists of a cleaned and preweighed filter crucible (or membrane filter assembly), rubber crucible holder, and suction flask. The bottle or ampoule is opened and the contents are transferred to the crucible with the aid of a stirring rod and rubber "policeman." The sides of the container are scraped thoroughly during this operation and during the rinsing to quantitatively remove all of the adhering precipitate. If filtration is slow, the filtrate is sampled and acidified for AAS analysis without waiting for completion of the filtration. Very slow filtrations will invalidate the solids determination; in these cases the concentration of silica retained by the filtrate will be the only useful measurement.

When the filtrate is sampled, it is acidified with $1 \mathrm{ml}$ concentrated $\mathrm{HCl}$ per $100 \mathrm{ml}$ of filtrate and then analyzed by AAS as described below. After filtrate sampling, the brine container is rinsed three times with water into the crucible, the crucible and its contents are rinsed five times with small portions of water, and then the crucible is placed in an oven at $105-110^{\circ} \mathrm{C}$ to dry. After heating for $>12 \mathrm{~h}$, the crucible is weighed and the concentration of solids calculated on the basis of the weight of the brine that was filtered.

\section{DETERMINATION OF SILICON IN BRINE BY AAS}

Two reagents are required: reagent-grade $\mathrm{HCl}$ and a $1000 \mathrm{mg} / \mathrm{l}$ standard solution of silicon, such as Fisher Scientific No. SO-S-465. The method of standard additions is used.

A $5-\mathrm{ml}$ aliquot of the acidified filtrate and a $0.5-\mathrm{ml}$ portion of concentrated $\mathrm{HCl}$ are pipetted into each of four $50-\mathrm{ml}$ volumetric flasks. To three of the flasks, standard solution aliquots of $0.5,1$, and $2 \mathrm{ml}$ are added to give final concentrations of 10,20 , and $40 \mathrm{mg} / 1$. No silicon is added to the fourth flask.

The four solutions are then analyzed with the atomic absorption spectrophotometer using a fuelrich nitrous oxide-acetylene flame, a wavelength of $251.6 \mathrm{~nm}$, and a slit width of $0.2 \mathrm{~nm}$. The observed absorbances are plotted vs the concentrations of the added silicon, and the silicon in the unknown solution is found from the intercept of the line at the zero absorbance level. The silica concentration of the brine is calculated from the silicon concentration found by analysis and is usually reported as milligrams of $\mathrm{SiO}_{2}$ per kilogram of brine.

\section{CHARACTERISTICS OF SILICA AND SOLIDS DETERMINATIONS}

The analyses of geothermal brines for suspended solids and silica in this manner provide very useful data for studies of scaling inhibitors, injectability, and reactor-clarifier operation. The solubility of silica in the brine at a given temperature has also been required. Therefore it has been of interest to determine the characteristics of these solids and silica measurements with respect to (a) the sizes of particles retained by the glass filter crucible and (b) the sizes of particles of silica registered by AAS. To answer these questions, some comparisons were made between filtrations with the glass crucibles and filtrations with 1-and $5-\mu \mathrm{m}$ Nucleopore membrane filters.

When brines containing suspended particulates of black, heavy-metal sulfides were first filtered through a $1-\mu \mathrm{m}$ membrane filter, visual observation indicated that the filtrate still contained particulates. When portions of the same brines - were filtered through the fine-porosity glass crucibles, the solutions were clarified; thus particles smaller than $1 \mu \mathrm{m}$ are removed by the glass filter, at least when a filter cake is present. Calculations show that the total mass fraction of particles in the $0.1-$ to $1.0-\mu \mathrm{m}$ range is small, so the values reported for solids filtered through the nominal 5- $\mu \mathrm{m}$ glass crucibles are probably nearly the same as values that would be obtained by filtration through $1-\mu \mathrm{m}$ surface-type membrane filters.

To investigate the effect of silica particle size on the determination of silicon by AAS, we examined a brine acidified to $\mathrm{pH} 4.5$ to decrease the rate of silica precipitation. This brine was incubated at $90^{\circ} \mathrm{C}$ and was repeatedly analyzed over a period of time, both before and after filtration through a $5-\mu \mathrm{m}$ Nucleopore membrane filter. In addition, the particle count in the solution before filtration was followed by means of a laser particle counter (Spectrex model ILI-1000). The initial concentration of $\mathrm{SiO}_{2}$ was found to be $526 \pm 20 \mathrm{mg} / \mathrm{kg}$. Table I gives the values for the $\mathrm{SiO}_{2}$ concentration measured at various times, together with the number of particles in the 5 - to $30-\mu \mathrm{m}$ range in the unfiltered brine as calculated 
TABLE 1. Silica concentration in filtered and unfiltered brine (determined by AAS) and particle count in unfiltered brine, during an 8.5-h period (5- $\mu \mathrm{m}$ Nucleopore filter; $\mathrm{pH} 4.5$ brine).

\begin{tabular}{|c|c|c|c|}
\hline \multirow[b]{2}{*}{ Time, $h$} & \multicolumn{2}{|c|}{ Concentration of $\mathrm{SiO}_{2}, \mathrm{mg} / \mathrm{kg}$} & \multirow[b]{2}{*}{$\begin{array}{l}\text { Particles in 5- to } 30-\mu \mathrm{m} \\
\text { range, per } \mathrm{cm}^{3}\end{array}$} \\
\hline & Unfiltered & $\begin{array}{c}\text { Filtered } \\
\text { ("dissolved silica") }\end{array}$ & \\
\hline 0 & 526 & 526 & 212 \\
\hline 1 & 526 & 526 & 242 \\
\hline 3 & 526 & 526 & $\cdots$ \\
\hline 5 & 526 & 526 & 658 \\
\hline $8.5^{\mathrm{a}}$ & 516 & 470 & 447. \\
\hline
\end{tabular}

aSolution faintly turbid.

from the laser counter data. The number of particles in the solution increased until $\sim \mathbf{4}$ after sampling, when flocculation began to occur. Even though most of the particles in the 5- to $30-\mu \mathrm{m}$ range are removed by the filter, there is no apparent decrease in the AAS value for $\mathrm{SiO}_{2}$ until flocculation is well underway. The reason for this is that these particles contribute very little to the total amount of silica at these early times; e.g., a concentration of $50010-\mu \mathrm{m}$ particles $/ \mathrm{cm}^{3}$ is only $\sim 0.5 \mathrm{ppm} \mathrm{SiO}_{2}$.
When visible turbidity appeared in the brine at $\sim 8 \mathrm{~h}$, the first decrease in the quantity of $\mathrm{SiO}_{2}$ determined by AAS occurred. Because the value of $\mathrm{SiO}_{2}$ concentration for the unfiltered solution at $8.5 \mathrm{~h}$ is only slightly smaller than the values taken earlier (see Table 1) and the value for the filtered solution is still lower, it appears that particles at least as large as the $5-\mu \mathrm{m}$ size removed by the filter are registered by AAS. Thus all of the silica passed by the porous glass filter, whether monomeric, polymeric, or particulate, is determined by AAS. Since the glass filter crucibles remove essentially all of the particulates $>1 \mu \mathrm{m}$ in size, the concentrations of "dissolved silica" that we report for the filtrates represent a distribution of particle sizes $<1 \mu \mathrm{m}$. When the brines have reached equilibrium at a given temperature, the measurements of filtrate $\mathrm{SiO}_{2}$ by AAS appear to be fairly accurate values for the effective solubility of amorphous silica. Also, recent measurements of monomeric silica in brines that were analyzed promptly, before particle growth occurred, have shown good agreement between the silicomolybdate spectrophotometric results and those obtained by AAS.

The standard deviations of determinations of filtered solids and silica in solution by the techniques described are 13 and $6 \mathrm{mg} / \mathrm{kg}$, respectively, as calculated from pairs of measurements of duplicate bottled samples in the range of 50 to $500 \mathrm{mg} / \mathrm{kg}$.

\section{SOME RESULTS OF SILICA AND SOLIDS DETERMINATIONS}

The reports previously cited ${ }^{1-5}$ contain a number of examples of the results of the measurement techniques described here. These techniques have also been used to determine the effect of brine salinity on the solubility of silica in the hypersaline brines. To illustrate the type of data obtained, the results of a more recent measurement of the kinetics of the precipitation of solids and silica from Woolsey No. 1 brine are shown in Fig. 4. Note that the initial rate of precipitation is very high; it is typical of the brines containing $>4.0 \mathrm{~mol}$ chloride/liter that during the first $15 \mathrm{~min}$ after sampling, the solid concentrations reach at least $50 \%$ of their final values, and the dissolved silica concentrations decline to $50 \%$ of the initial values. However, quite long times ( $>30$ days) are required to reach final equilibrium at $90^{\circ} \mathrm{C}$. Thus solubility data are based on these one-month incubations. $^{8}$
Some data on the solubility of silica in the Woolsey brine as a function of temperature are shown in Fig. 5. In this temperature range, the solubility is quite sensitive to temperature. It is of interest to know the solubility at higher temperatures, but, as noted earlier, such measurements require pressurized equipment.

The solids precipitated from untreated, anoxic, hypersaline brine are composed primarily of amorphous silica, ranging from 80 to $97 \%$ by weight as $\mathrm{SiO}_{2}{ }^{8}$ An unidentified iron compound, $2-5 \%$ as $\mathrm{Fe}$, also is always present. Loss of weight on heating above $105^{\circ} \mathrm{C}$ in an inert atmosphere indicates that 3-8\% additional moisture is present. A few percent $\mathrm{CO}_{2}$ is evolved on treatment with acid, thus some of the metals are present as carbonates. Woolsey No: 1 brine differs from Magmamax No. 1 brine in containing $\sim 90 \mathrm{mg} / \mathrm{kg}$ of sulfate which, together with 


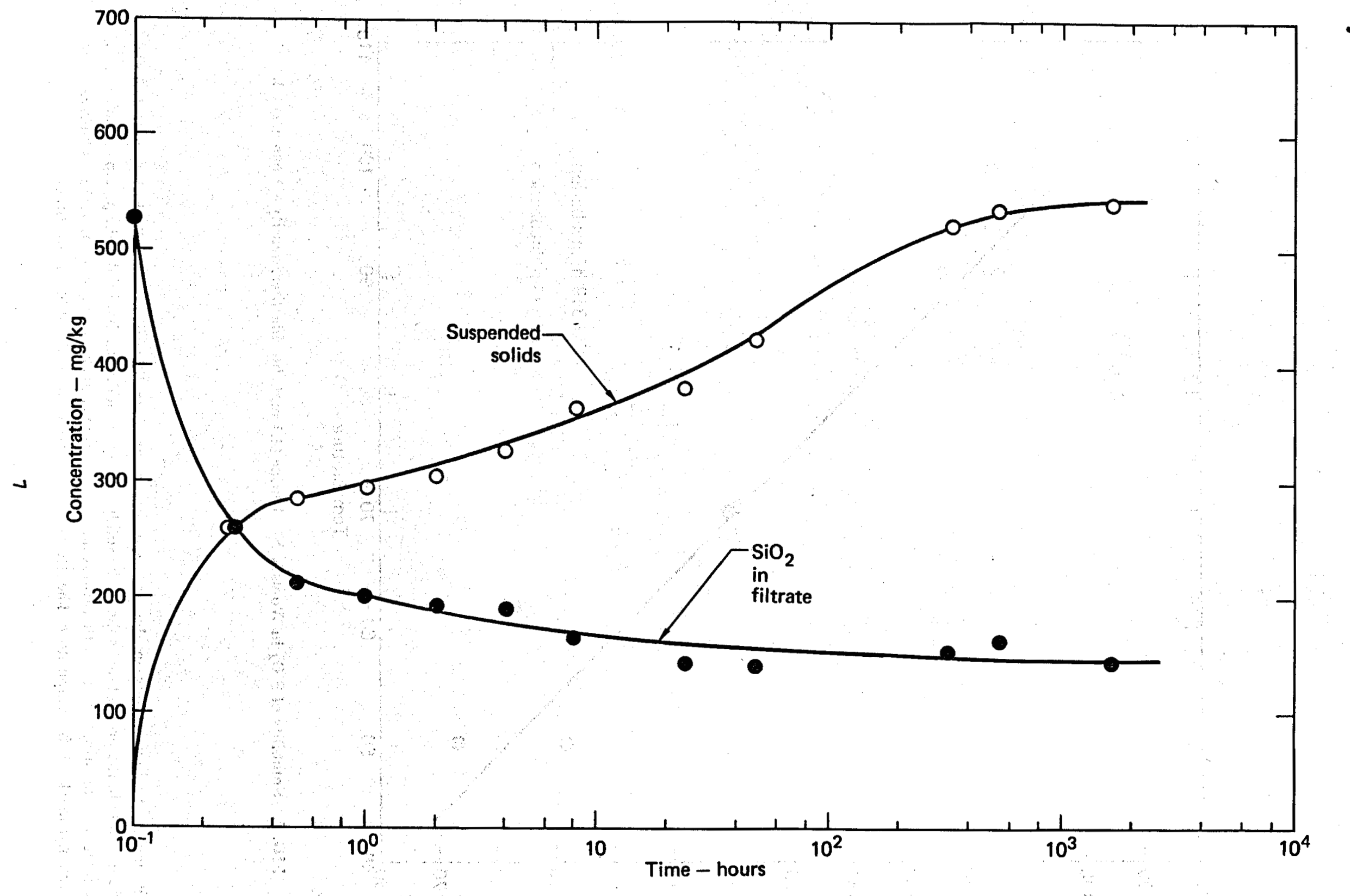

FIG. 4. Concentration of suspended solids and dissolved $\mathrm{SiO}_{2}$ in effluent brine after incubation at $90^{\circ} \mathrm{C}$ (Woolsey No. 1 brine, 4.1 mol chloride/liter). 


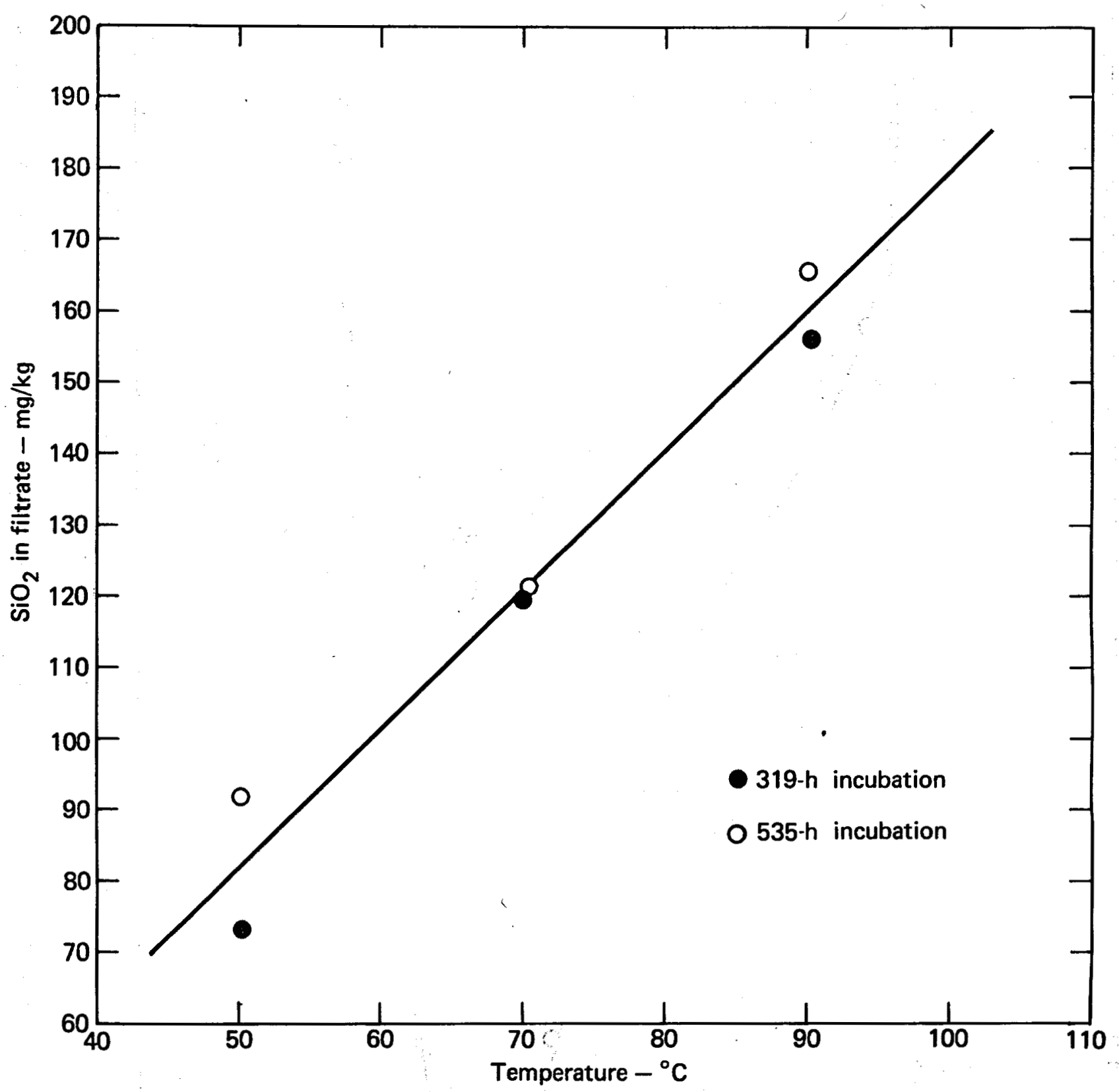

FIG. 5. Solubility of $\mathrm{SiO}_{2}$ in Woolsey No. 1 brine $\left(4.1 \mathrm{~mol}\right.$ chloride $/$ liter, density $\left.=1.666 \mathrm{~g} / \mathrm{cm}^{3}\right)$.

$\sim 150 \mathrm{mg} / \mathrm{kg}$ barium, results in the presence of barium sulfate in the precipitated solids. The solids precipitated from brine treated with various additives change markedly in composition. The effects of brine acidification were described previously. ${ }^{8}$ Organic additives that inhibit the precipitation of silica decrease its proportion in the solids and increase the proportions of the other constituents. 


\section{ACKNOWLEDGMENTS}

Chemical analyses of the precipitated solids were carried out by R. W. Ryon, W. J. Beiriger, L. J. Gregory, and P. C. Crawford.

\section{REFERENCES}

1. A. L. Austin, A. W. Lundberg, L. B. Owen, and G. E. Tardiff, The LLL Geothermal Energy Status Report, January 1976-January 1977, Lawrence Livermore Laboratory, Livermore, CA, UCRL-50046-76 (1977), pp. 94-97.

2. J. E. Harrar, C. H. Otto, Jr., J. H. Hill, C. J. Morris, R. Lim, and S. B. Deutscher, Determination of the Rate of Formation of Solids from Hypersaline Geothermal Brine as a Function of $p H$, Lawrence Livermore Laboratory, Livermore, CA, UCID-17596 (1977).

3. J. E. Harrar, L. E. Lorensen, C. H. Otto, Jr., S. B. Deutscher, and G. E. Tardiff, "Effects of Organic Additives on the Formation of Solids from Hypersaline Geothermal Brine," Trans. Geotherm. Resour. Council Mig., Hilo, Hawaii, 1978 (Geothermal Resources Council, Davis, CA, 1978), pp. 259-262.

4. J. E. Harrar, F. E. Locke, C. H. Otto, Jr., L. E. Lorensen, S. B. Deutscher, W. P. Frey, and R. Lim, "Field Tests of Organic Additives for the Control of Scale at the Salton Sea Geothermal Field," Trans. Geotherm. Resour. Council Mtg., Reno, Nevada, 1979 (Geothermal Resources Council, Davis, CA, 1979).

5. E. Raber, L. B. Owen, and R. Lim, "Injection R \& D," LLL Geothermal Industrial Support Program, FirstQuarter Technical Progress Report for FY1979, Lawrence Livermore Laboratory, Livermore, CA, UCID18074-79-1 (1979), pp. 37-56.

6. American Society for Testing Materials Standard Test Method E128-61 (1969).

7. J. Grens, Preliminary Tests Using a Laser Particle-Size Analyzer in Geothermal Brine, Lawrence Livermore Laboratory, Livermore, CA, UCID-17637 (1977).

8. J. E. Harrar, C. H. Otto, Jr., S. B. Deutscher, R. W. Ryon, and G. E. Tardiff, Studies of Brine Chemistry, Precipitation of Solids, and Scale Formation at the Salton Sea Geothermal Field, Lawrence Livermore Laboratory, Livermore, CA, UCRL-52640 (1979).

$\mathrm{CJT} / \mathrm{gw}$ 